\title{
ORIGINAL ARTICLE Revisiting early hypothyroidism screening in infants with Down syndrome
}

\author{
IB Purdy ${ }^{1}$, N Singh ${ }^{1}$, WL Brown ${ }^{1}$, S Vangala ${ }^{1,2}$ and UP Devaskar ${ }^{1}$
}

OBJECTIVE: To identify if the incidence of hypothyroidism in infants with Down syndrome is higher than previous childhood estimates (15\%) when examined prior to the standard retesting at 6 months of age.

STUDY DESIGN: A retrospective observational cohort study of 122 children with Down syndrome admitted to a university-based birthing hospital between May 2000 and March 2012. Demographic data (for example, date of birth, gender, gestational age, inborn) and diagnostic data (Down syndrome, congenital heart disease and gastrointestinal disease) were cross-linked with thyroid hormone laboratory tests (total thyroxine, free thyroxine and thyroid stimulating hormone) to determine incidence of identified hypothyroidism and thyroid testing prior to 4 months of age $(n=80)$.

RESULT: In all, 32.5\% were found to have any hypothyroidism. Of these, 14 were primary hypothyroidism (17.5\%) needing supplemental T4 therapy, 12 were compensated hypothyroidism (15\%) and euthyroid was identified in 54 infants (67.5\%). CONCLUSION: Despite normal newborn screens, the incidence of any hypothyroidism (early compensated hypothyroidism and primary hypothyroidism) was higher than previously reported.

Journal of Perinatology (2014) 34, 936-940; doi:10.1038/jp.2014.116; published online 19 June 2014

\section{INTRODUCTION}

Down syndrome, Trisomy 21 , is the most frequent inherited form of cognitive impairment and learning disability. ${ }^{1}$ Down syndrome is a common genetic disorder affecting $\sim 10000$ babies or 1 in 700 live births in the United States of America each year. ${ }^{2-4}$ Recent estimates report that there are over 40000 people with Down syndrome living in the United States of America and over 6 million people worldwide. ${ }^{5}$ Although clinical presentation may vary, Down syndrome is associated with several congenital anomalies, including cardiovascular, gastrointestinal, metabolic and endocrine systems and mental retardation. ${ }^{2}$ Among the endocrine disorders associated with Down syndrome, those affecting thyroid function are most frequent. ${ }^{2-9} \mathrm{~A}$ thorough discussion of these health concerns associated with Down syndrome as well as agespecific recommendations for health monitoring are provided by the American Academy of Pediatrics (AAP), which recommends thyroid hormone testing for Down syndrome infants at birth and at 6 and 12 months of age. ${ }^{6,7}$ After the AAP guideline re-release in 2001 , a population-based study found a $73 \%$ increase in the incidence of medically treated thyroid disease in children (1 to 18 years of age) with Down syndrome (13.25\% in 1995 to $23.5 \%$ in 2005). ${ }^{3}$ The increased prevalence of hypothyroidism, compensated hypothyroidism subclinical or transient (that is, increased plasma thyroid stimulating hormone (TSH) with normal thyroid hormone concentration) is well documented, ${ }^{9-11}$ with hypothyroidism being the most common. ${ }^{1-10}$ Persistent congenital hypothyroidism, detected by newborn metabolic screening, is approximately 28 times more common among infants with Down syndrome ( $1 \%$ incidence, $0.7 \%$ permanent and $0.3 \%$ transient). ${ }^{12,13}$ In addition, marginally low T4 concentration by newborn metabolic screening has been reported in newborns with Down syndrome. ${ }^{12,13}$ Rates of occurrence of hypothyroidism in patients with Down syndrome vary between study designs and patient ages and report significant increases in occurrence of hypothyroidism among patients with Down syndrome with a lifetime prevalence range between 13 and $63 \% .{ }^{9-11,14-16}$ Although early childhood prevalence rates of any thyroid dysfunction in Down syndrome is estimated to be $15 \%$, estimates in early infancy as high as $85 \%$ were based on elevated TSH levels obtained just after the newborn screening period with Down syndrome children. ${ }^{17}$ As TSH surge occurs shortly after birth, the routine newborn screening test may not be the definitive reflection of thyroid function for diagnosing congenital hypothyroidism. An important gap in these studies is the lack of evaluation of thyroid function after the newborn screen and before 6 months of age.

To wait until 6 months of age to retest infants with Down syndrome may not be the best decision if consideration is given to the individual or societal cost/benefit ratio. Thyroid hormones are vital for the development of the central nervous system, particularly during infancy, as they affect neuronal migration and differentiation, activation of the sympathetic nervous system, synthesis and secretion of neurotransmitters and myelination. ${ }^{18}$ Untreated hypothyroidism may aggravate several manifestations associated with Down syndrome during infancy and childhood, such as psychomotor development, somatic growth and mental retardation. It is likely that hypothyroidism may not be suspected in infants with Down syndrome because it is often difficult to distinguish physical symptoms and signs related to hypothyroidism from similar characteristics seen in infants with Down syndrome (that is, feeding difficulties, decreased physical activity, hypotonia, macroglossia and developmental delays). ${ }^{14,15}$ The standardized newborn screening drastically changed the natural

'Division of Neonatology, Department of Pediatrics, David Geffen School of Medicine at UCLA, Mattel Children's Hospital, University of California, Los Angeles, Los Angeles, CA USA and ${ }^{2}$ Department of Medicine Statistics Core, David Geffen School of Medicine at UCLA, Mattel Children's Hospital, University of California, Los Angeles, Los Angeles, CA, USA. Correspondence: Dr IB Purdy, Division of Neonatology, Department of Pediatrics, David Geffen School of Medicine at UCLA, Mattel Children's Hospital, University of California, Los Angeles, 10833 Le Conte Avenue, B2-375 MDCC, Los Angeles, 90095-1752 CA, USA. 
history of congenital hypothyroidism, which represents the most common preventable cause of high risk for mental retardation. ${ }^{14,15}$ Risk for mental retardation is increased if hypothyroidism treatment is delayed beyond 3 months of age. ${ }^{14,15}$ Past studies identified that 5 to $10 \%$ of babies with congenital hypothyroidism go undiagnosed based on false-negatives on the newborn screening tests. ${ }^{17}$

In the year 2000, we diagnosed primary hypothyroidism at approximately 1 month of age in a baby with Down syndrome who had normal thyroid hormone on the newborn screening at birth. Despite normal thyroid hormone test results on the newborn metabolic screening at birth, hypothyroidism was previously reported to occur in a 3-month-old infant with Down syndrome. ${ }^{19}$ Based on this information, our institution started rescreening the majority of babies with Down syndrome before 6 months of age for hypothyroidism who had a normal thyroid hormone screen at birth. We conducted an observational study with the objective of identifying the incidence of any hypothyroidism among infants with Down syndrome between 3 and 120 days of life who were admitted to the Mattel Children's Hospital UCLA between 2000 and 2012

\section{METHODS}

Study sample

Electronic medical records and clinical databases were used to identify infants with Down syndrome who were admitted to Mattel Children's Hospital at UCLA between May 2000 and March 2012. Admissions to general pediatrics, neonatal intensive care and pediatric intensive care were included. The UCLA Office of the Human Research Protection Program Institutional Review Board approved this study. Baseline thyroid tests obtained on state newborn screens and hospital laboratory thyroid tests ordered post newborn screen and by 4 months of age (range 3 to 120 days of age) were included in the analysis. Primary diagnoses obtained from the clinical database and electronic medical records provided background data, which were cross-linked with newborn screening records and laboratory tests.

Serum TSH and free thyroxine (free T4) and total thyroxine (total T4) concentrations were measured by the standard laboratory methods well established at our institution as follows. Determination of serum TSH is performed by electrochemiluminesence immunoassay on Elecsys 2010 and Cobas e 411 analyzers according to the TSH assay standard against the Second International Reference Standard 80/558 and the Cobas immunoassay analyzers (Roche Diagnostics, Indianapolis, IN, USA) methods. The manufacturer indicates the TSH assay cross-reactivity for the following hormones: lutinizing hormone, follicle stimulating hormone, human growth hormone and human chorionic gonadotropin was $0.038 \%, 0.008 \%, 0 \%$ and $0 \%$, respectively. For the total T4 assay, the cross-reactivity for the rapid acting thyroid hormone liothyronine Triiodothyronine (L-T3) and Triiodothyronine (D-T3) was $1.3 \%$ and $0.8 \%$, respectively. Free T4 assay cross-reactivity was $1.53 \%$ for thyroid hormones L-T3 and D-T3. No data for cross-reactivity with any other proteins was indicated. Repeat testing for plasma TSH, Free T4 and Total T4 was performed at different ages at the discretion of the physician, and evaluated by standards for normal agespecific ranges established in our laboratory. Infants with Down syndrome were then grouped into four categories based on the results of age-specific plasma thyroid hormone results: (1) Euthyroid: normal TSH and total T4, (2) Primary hypothyroidism: high TSH and low total T4, (3) Compensated hypothyroidism: high TSH and normal total T4, and (4) Sick thyroid syndrome: low TSH and low T4. The principle investigators established interrater reliability among the research team members for data abstraction on all laboratory results and hypothyroidism subgroup classifications.

\section{Statistical methods}

Data analyses were performed using STATA 8 and SAS v 9.3 for crosstabulations, $X^{2}$-test or analysis of variance among different groups. Descriptive statistics were employed to explain data findings based on means, standard deviations and 95\% confidence intervals and the medians, interquartile range and range for the proportion of subjects identified as euthyroid, primary hypothyroidism or compensated hypothyroidism.

\section{RESULTS}

We identified a total of 122 infants with Down syndrome during this time period. Table 1 displays the sample characteristics and identified timing of thyroid testing if conducted. The gender was fairly equally distributed. The mean birth weight was $2663 \mathrm{~g} \pm 821$. The mean gestational age at birth was 36.5 weeks. Many had birth defect co-morbidities, such as cardiovascular (57\%) and gastrointestinal (23\%) disorders. The majority was inborn (54\%). The average length of hospital stay was 27 days. One baby who was diagnosed with hypothyroidism at birth was treated with T4 and the data was excluded from the analysis. Except one, all babies were euthyroid at birth (that is, normal TSH at birth, newborn screening). The exact TSH level was available in 45 patients $\left(5.4 \mu \mathrm{UU} \mathrm{ml}^{-1}\right)$. Out of the total sample, $80(66 \%)$ had repeat serum plasma TSH and total T4 or free T4 levels tested between 3 and 120 days of age. In these patients, the euthyroid, primary or compensated hypothyroidism or sick thyroid syndrome status was determined. The decision to treat with supplemental T4 $(n=14)$ was made in consultation with the Pediatric Endocrinologist. There were 54 euthyroid (67.5, confidence interval 57.2, 77.8\%), 14 primary hypothyroidism (17.5, confidence interval 9.2, 25.8\%) and 12 compensated hypothyroidism (15, confidence interval 7.2, $22.8 \%$ ) infants. Two premature babies died within 7 days of age and two babies were diagnosed with sick thyroid syndrome. The youngest age at which a baby with primary hypothyroidism was diagnosed was 7 days (range 7 to 119). Table 2 depicts the median, interquartile range and range for the highest and lowest levels of thyroid hormone concentrations identified in this sample. Table 3 identifies the percentage of this sample with the three primary thyroid diagnoses.

Table 4 shows that the incidence of hypothyroidism in this study was not affected by gender, cardiovascular or gastrointestinal disease.

\section{DISCUSSION}

Our main finding is that infants with Down syndrome are likely to be at higher risk for development of hypothyroidism at least months before the AAP recommendations to retest at 6 months of age. Although there are reports of this occurring in the clinical setting, there are no reports today describing development of any hypothyroidism (32.5\%) between 3 and 120 days of life within this population, whose newborn screening tests were normal. Recent reports indicate an increasing incidence of congenital primary hypothyroidism in the United States among normal newborn babies. $^{20}$ It is unknown if the overall incidence of congenital hypothyroidism is also increasing among neonates with Down syndrome or if improvement in early screening results in better identification of the true incidence at birth.

The etiology of primary hypothyroidism in older children with Down syndrome is thought to be due to abnormal autoimmune

Table 1. Perinatal characteristics and repeat thyroid tests in infants with Down syndrome $(n=122)$

\begin{tabular}{lc}
\hline Infant characteristics & Number (\%) or mean \pm s.d. \\
\hline Birth weight $(\mathrm{kg})$ & $2.66 \pm 0.82$ \\
Gestational age (weeks) & $36.5 \pm 2.9$ \\
Congenital gastro intestinal disease & $28(23 \%)$ \\
Congenital heart disease & $69(57 \%)$ \\
Inborn & $66(54 \%)$ \\
Repeat TSH 3-120 days of life & $80(66 \%)$ \\
Repeat TSH not-tested & $42(34 \%)$ \\
Repeat TSH/TH (days) & $36 \pm 37$ \\
Highest TSH (days) & $36 \pm 40$ \\
\hline
\end{tabular}


Table 2. Repeat serum thyroid test results between 3 and 120 days of age in infants with Down syndrome $(n=80)$

\begin{tabular}{lccc}
\hline Thyroid tests & Euthyroid $(\mathrm{n}=54)$ & Hypothyroidism needing treatment $(\mathrm{n}=14)$ & Compensated hypothyroidism $(\mathrm{n}=12)$ \\
\hline $\begin{array}{l}\text { Highest TSH }(\mu / \mathrm{U} / \mathrm{ml}) \\
\quad \text { Median }(\mathrm{Q} 1, \mathrm{Q})\end{array}$ & $5.65(3.5,10.4)$ & $22.2(11.5,42.2)$ & $14(10.7,17.4)$ \\
$\quad$ Minimum, maximum & $0.4,42.9$ & $3.3,216.5$ & $7.1,41.4$ \\
Lowest Total T4 (mcg/dl) & & & $10.5(10.2,11.9)$ \\
$\quad$ Median $(\mathrm{Q} 1, \mathrm{Q} 3)$ & $9.6(4.6,14.4)$ & $7.2(1.8,7.7)$ & $9.6,12.3$ \\
$\quad$ Minimum, maximum & $1.4,17.1$ & $1,12.3$ & $1.6(1,1.9)$ \\
$\begin{array}{l}\text { Lowest free T4 (ng/dl) } \\
\text { Median }(\mathrm{Q} 1, \mathrm{Q} 3)\end{array}$ & $1.5(0.9,1.9)$ & $1.5(1.3,1.8)$ & $1,1.9$ \\
Minimum, maximum & $0.8,2.3$ & $1.3,1.8$ & \\
\hline
\end{tabular}

\begin{tabular}{|c|c|c|c|c|c|c|}
\hline $\begin{array}{l}\text { Gender } \\
\text { Male } \\
\text { Female }\end{array}$ & $\begin{array}{r}10(58.8 \%) \\
7(41.2 \%)\end{array}$ & $\begin{array}{l}49(51.6 \%) \\
46(48.4 \%)\end{array}$ & 0.5816 & 1.341 & 0.471 & 3.818 \\
\hline $\begin{array}{l}\text { Congenital heart disease } \\
\text { Yes } \\
\text { No }\end{array}$ & $\begin{array}{r}10(58.8 \%) \\
7(41.2 \%)\end{array}$ & $\begin{array}{l}56(59.0 \%) \\
39(41.0 \%)\end{array}$ & 0.9924 & 0.995 & 0.349 & 2.840 \\
\hline $\begin{array}{l}\text { Gastrointestinal anomalies } \\
\text { Yes } \\
\text { No }\end{array}$ & $\begin{array}{r}5(29.4 \%) \\
12(70.6 \%)\end{array}$ & $\begin{array}{l}22(23.2 \%) \\
73(76.8 \%)\end{array}$ & 0.5519 & 1.383 & 0.439 & 4.354 \\
\hline
\end{tabular}

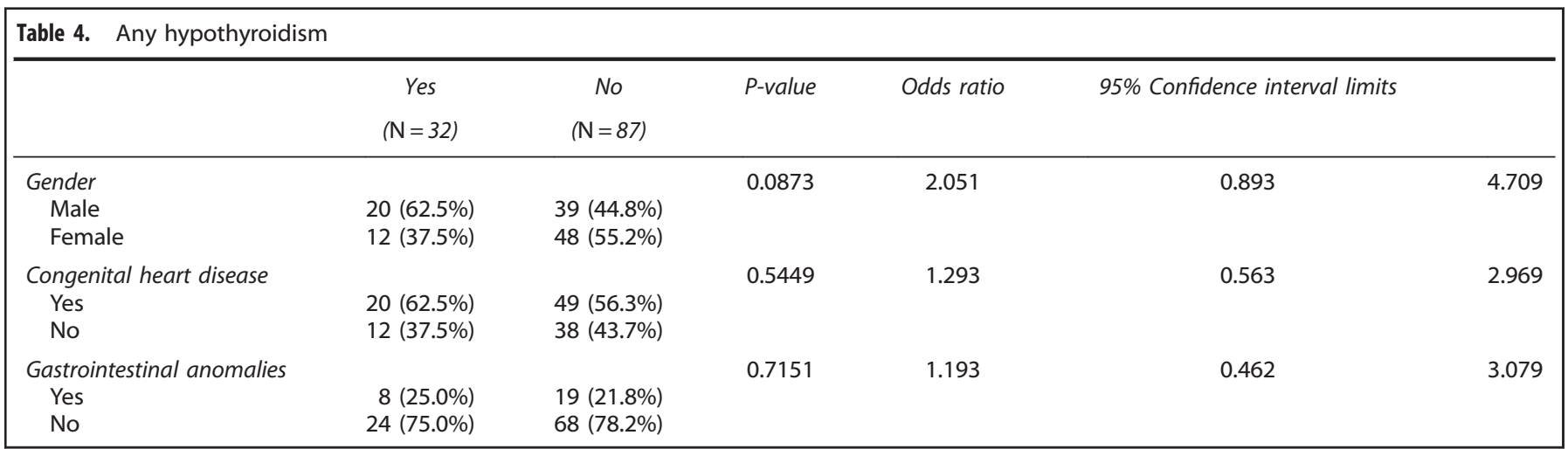

function. ${ }^{2,8-11}$ In our study, the phenomenon of primary hypothyroidism was observed among $17.5 \%$ of infants prior to 4 months of age. Mechanisms of primary or compensated hypothyroidism observed between 3 and 120 days of age in our study remain unknown and need further investigation. Infants with Down syndrome have a greater prevalence of compensated hypothyroidism during the first few months of life..$^{2,8-11}$ Most infants with Down syndrome are not detected by newborn screening because their T4 levels are just above normal or their TSH levels are just below cutoff values..$^{8-12,20-21}$ Compensated hypothyroidism in children with Down syndrome has been typically reported in later childhood with wide variability in range from 6 to $30 \%$ and higher. ${ }^{11,16,22-29}$ One study referring to the relatively high prevalence of congenital hypothyroidism in Down syndrome infants reported that it tended to occur in those with gastrointestinal anomalies. ${ }^{27}$ We did not observe a significant difference in the incidence of hypothyroidism prior to 4 months of age among Down syndrome infants with gastrointestinal anomalies compared with those without gastrointestinal defects. Nor did we find any significant difference when comparing incidence of hypothyroidism by congenital heart disease (Table 4). We found a higher incidence of hypothyroidism among male infants compared to females. Others have reported striking differences in hypothyroidism incidence in Down syndrome children by race and age. ${ }^{3}$ African-American children with Down syndrome were less likely to be diagnosed and medically treated for thyroid disease than white children. ${ }^{3}$ It is unclear if this is a result of disease incidence or just a not rescreening. ${ }^{3}$

Rescreening between 1-3 years of age is easier due to more frequent well child checks and may influence the highest incidence occurring in this age group. In addition, physicians may be more likely to prescribe medication for young children 
with abnormal thyroid function studies as children less than age three are particularly vulnerable to the adverse effects of untreated hypothyroidism on intellectual development. The natural progression of compensated hypothyroidism includes conversion to euthyroid or primary hypothyroidism state. ${ }^{11,16,22-26}$

In 1985, Pueschel and Pezzullo ${ }^{28}$ identified 151 children with Down syndrome and their sibling controls 3 to 21 years old. They found $27 \%$ had an abnormality of TSH, T4 or both and noted that adolescents had higher TSH concentrations and decreasing T4 levels with advancing age. They questioned whether previously reported intellectual decline in this population was, in part, due to undetected and inadequate thyroid function. ${ }^{28}$ In 1993, Selikowitz ${ }^{29}$ examined the elevation of TSH when T4 and T3 levels were normal to determine whether this affected growth or intellectual performance and found no difference between Down syndrome children with and without elevated TSH. In 1991, Pueschel updated his study to include a total of 181 patients and found that $6 \%$ of children had both high TSH and low T4.

Limitations of this study include that we did not evaluate these infants beyond 4 months of age. We recognize the need for further studies to more fully understand the early mechanisms of compensated hypothyroidism in infants with Down syndrome and to prospectively examine the potential impact on long-term development. Early treatment of hypothyroidism in otherwise normal babies with supplemental T4 prevents brain damage. ${ }^{18}$ With earlier rescreening, this treatment could potentially be offered during the neonatal period in children with Down syndrome and may modestly improve psychomotor development and growth in infancy. ${ }^{22}$ However, at this time, it is not known if earlier recognition and treatment of primary hypothyroidism with supplemental T4 would improve long-term neurologic outcome in this population. In the study by van Trotsenburg et $a l_{.}{ }^{22}$ the thyroid hormone status of neonates with Down syndrome prior to supplementing T4 was not established. It is likely that some babies with normal thyroid function were treated unnecessarily and the side effects of long-term T4 therapy are not benign. ${ }^{26}$

\section{CONCLUSION}

This current study adds to the body of knowledge on clinical incidence of early hypothyroidism in infants with Down syndrome. This study provides pilot support for future research to prospectively examine the incidence in a large population-based study to determine cost/benefit ratios of early testing and to identify if it would be worthwhile reconsidering earlier testing.

\section{SUMMARY}

Of clinical significance, we speculate that in infants with Down syndrome, despite a normal test on newborn screening, primary or compensated hypothyroidism may be more common now and occur earlier than previously recognized.

- Early hypothyroidism and its morbidity within this population may go unrecognized.

- Health-care management of this vulnerable population can be a challenge to balance treatments and strive for optimal health and central nervous system development, and may require consideration of closer and earlier standardization for retesting for diagnosis of primary hypothyroidism.

\section{CONFLICT OF INTEREST}

The authors declare no conflict of interest.

\section{DISCLAIMER}

This manuscript represents original research. This manuscript has not been previously published or submitted for publication elsewhere while under consideration by the Journal of Perinatology.

\section{REFERENCES}

1 Bittles MJ, Glasson EJ. Clinical, social, and ethical implications of changing life expectancy in Down syndrome. Dev Med Child Neurol 2004; 46(4): 282-286.

2 Roizen NJ, Patterson D. Down's syndrome. Lancet 2003; 361(9365): 1281-1289.

3 Carroll K, Arbogast P, Dudley J, Cooper W. Increase in incidence of medically treated thyroid disease in children with Down syndrome after re-release of American Academy of Pediatrics health supervision guidelines. Pediatrics 2008; 122: e493-e498.

4 Parker SE, Mai CT, Canfield MA, Rickard R, Wang Y, Meyer RE et al. Updated National Birth Prevalence estimates for selected birth defects in the United States, 2004-2006. Birth Defects Res A. Clin Mol Teratol 88(12): 1008-1016.

5 National Down Syndrome Society. Down syndrome fact sheet 2012. Retrieved from http://www.ndss.org/index.php?option = com.content\&view = article \&ide = 54\&Itemid = 74. 2012.

6 Bull MJ. Health supervision for children with Down syndrome. Pediatrics 2011; 128 (2): 393-406.

7 American Academy of Pediatrics Committee on Genetics. Health supervision for children with Down syndrome. Pediatrics 2001; 107(2): 442-449.

8 Gibson PA, Newton RW, Selby K, Price DA, Leyland K, Addison GM. Longitudinal study of thyroid function in Down's syndrome in the first two decades. Arch Dis Child 2005; 90(6): 574-578.

9 Gruneiro de Papendieck L, Chiesa A, Bastida MG, Alonso G, Finkielstain G, Heinrich JJ. Thyroid dysfunction and high thyroid stimulating hormone levels in children with Down's syndrome. J Pediatr Endocrinol Metab 2002; 15: 1543-1548.

10 Karlsson B, Gustafsson J, Hedov G, Ivarsson SA, Anneren G. Thyroid dysfunction in Down's syndrome: relation to age and thyroid autoimmunity. Arch Dis Child 1998; 79: 242-245.

11 Rubello D, Pozzan GB, Casara D, Girelli ME, Boccato S, Rigon F et al. Natural course of subclinical hypothyroidism in Down's syndrome: prospective study results and therapeutic considerations. J Endocrinol Invest 1995; 18(1): 35-40.

12 Fort $\mathrm{P}$, Lifshitz F, Bellisario R, Davis J, Lanes R, Pugliese $M$ et al. Abnormalities of thyroid function in infants with Down syndrome. J Pediatr 1984; 104: 545-549.

13 van Trotsenburg AS, Vulsma T, van Santen HM, Cheung W, de Vijlder JJ. Lower neonatal screening thyroxine concentrations in Down Syndrome newborns. J Clin Endocrinol Metab 2003; 88: 1512-1515.

14 Yunis K, Nasr M, Lepejaian G, Najjar S, Daher R. False-negative primary neonatal thyroid screening: the need for clinical vigilance and secondary screening. J Med Screen 2003; 10: 2-4.

15 Klein A, Meltzer S, Kenny F. Improved prognosis in congenital hypothyroidism treated before age three months. J Pediatrics 1972; 81: 912-915.

16 Sharav T, Collins RM Jr, Baab PJ. Growth studies in infants and children with Down's syndrome and elevated levels of thyrotropin. Am J Dis Child 1988; 142: 1302-1306.

17 Mattheis P Thyroid disease in Down's syndrome: clinical perspective, directions of research. 2nd International Symposium on Biomedical and Psychoeducational Aspects on Down Syndrome, Mexico City, 1997.

18 Oliveira A, Longui C, Calliari L, Ferone E, Kawaguti F, Monte O. Evaluation of the hypothalamic-pituitary-thyroid axis in children with Down syndrome. J Pediatr 2002; 78(4): 295-300.

19 Hardy O, Worley G, Lee MM, Chaing S, Mackey J, Crissman B et al. Hypothyroidism in Down syndrome: screening guidelines and testing methodology. Am J Med Genet A 2004; 124 A(4): 436-437.

20 Harris KB, Pass KA. Increase in congenital hypothyroidism in New York State and in the United States. Mol Genet Metab 2007; 91(3): 268-277.

21 van Trotsenburg AS, Kempers MJ, Endert E, Tijssen JG, de Vijlder JJ, Vulsma T. Trisomy 21 causes persistent congenital hypothyroidism presumably of thyroidal origin. Thyroid 2006; 16(7): 671-680.

22 van Trotsenburg AS, Vulsma T, van Rozenburg-Marres S, van Baar A, Ridder J, Heymans $\mathrm{H}$ et al. The effect of thyroxine treatment started in the neonatal period on development and growth of two-year-old Down syndrome children: a randomized clinical trial. J Clin Endocrinol Metab 2005; 90(6): 3304-3311.

23 Toledo C, Alembik Y, Dott B, Finck S, Stoll C. Anomalies of thyroid function in children with Down syndrome. Arch Pediatr 1997; 4: 116-120.

24 Jimenez-Lopez V, Arias A, Arata-Bellabarba G, Vivas E, Delgado MC, Paoli M. Concentration of thyrotropic hormone and free thyroxin in children with Down's syndrome. Invest Clin 2001; 42: 123-130. 
25 Crino A, Ciampalini P, DiGilio MC, Obregon MG, Giannotti A, Borrelli P. Abnormal thyrotropin secretion in Down's syndrome In: Castells S, Wisniewski KE (eds.) Growth Hormone Treatment in Down's Syndrome. John Wiley \& Sons: New York, 1993; 101-109.

26 Thiel R, Fowkes SW. Down syndrome and thyroid dysfunction: should nutritional support be the first-line treatment? Med Hypotheses 2007; 69: 809-815.

27 Jaruratanasirikul S, Patarakijvanich N, Patanapisarnsak C. The association of congenital hypothyroidism and congenital gastrointestinal anomalies in Down's syndrome infants. J Pediatr Endocrinol Metab 1998; 11: 241-246.

28 Pueschel SM, Pezzullo JC. Thyroid disfunction in Down syndrome. Am J Dis Child 1985; 139: 636-639.
29 Selikowitz M. A five-year longitudinal study of thyroid function in children with Down syndrome. Dev Med Child Neurol 1993; 35: 396-401.

(c) (i) $\odot$ This work is licensed under a Creative Commons Attributioncc. NonCommercial-NoDerivs 3.0 Unported License. The images or other third party material in this article are included in the article's Creative Commons license, unless indicated otherwise in the credit line; if the material is not included under the Creative Commons license, users will need to obtain permission from the license holder to reproduce the material. To view a copy of this license, visit http://creativecommons. org/licenses/by-nc-nd/3.0/ 